\title{
Otro punto en contra para la terapia de reemplazo hormonal
}

\author{
Breast cancer and hormone-replacement therapy in the Million Women Study. The Lancet 2003; 362:419-27).
}

\begin{abstract}
¿Por qué este estudio?
Hace un tiempo que venimos discutiendo en ateneos bibliográficos artículos sobre la terapia de reemplazo hormonal (TRH) con resultados que desalientan su utilización. Son de público conocimiento los resultados del HERS (TRH en prevención secundaria) y del WHI (TRH en prevención primaria) donde esta estrategia se asocia con un aumento del número de eventos cardiovasculares y trombóticos, así como de la incidencia de cáncer de mama. Los eventos cardiovasculares ocurrían principalmente dentro del primer año de iniciada la TRH y el riesgo de cáncer de mama parecía incrementarse luego de los tres años de recibirla.

Todavía existían algunos interrogantes sobre la TRH que los estudios hasta el momento no habían podido aclarar: 1) Su efecto sobre la mortalidad por cáncer de mama; 2) Si la TRH combinada se asociaba a mayor riesgo que la TRH con estrógenos solos; 3) Si el patrón de uso (secuencial o continuo) o los distintos tipos de componentes hormonales variaban el riesgo.
\end{abstract}

\section{El estudio del millón}

Para tratar de responder estas preguntas, los británicos diseñaron este estudio de cohortes donde enrolaron a 1084110 mujeres de 50 a 64 años desde 1996 hasta 2001. Junto con la carta de invitación al rastreo mamográfico de rutina cada tres años para todas las mujeres enviaron un cuestionario para ser respondido y devuelto antes de realizar la mamografía. Las mujeres fueron "marcadas" en los registros del Servicio Nacional de Salud para que cualquier caso de cáncer o muerte se notificara a los investigadores. El seguimiento promedio fue de 2,6 años para el análisis de la incidencia de cáncer y de 4,1 para el de la mortalidad, que fueron estratificados por edad y ajustados por tiempo desde la menopausia, paridad, antecedente familiar de primer grado con cáncer de mama, índice de masa corporal, uso previo de anticonceptivos orales y factores sociodemográficos. Los resultados analizados fueron el diagnóstico de cáncer de mama invasivo y las muertes atribuidas a cáncer de mama.

\section{Resultados}

Más del $50 \%$ del millón de mujeres (edad promedio: 56 años) había recibido $\mathrm{TRH}$ en algún momento.

\section{Riesgo relativo de incidencia de cáncer de mama invasivo}

\begin{tabular}{ll}
\hline No usadoras & 1 \\
$\begin{array}{l}\text { Usadoras durante el transcurso } \\
\text { del estudio }\end{array}$ & $1,66(1,60$ a 1,72$)$ \\
$\begin{array}{l}\text { Último uso durante los cinco } \\
\text { años previos }\end{array}$ & $1,04(0,95$ a 1,12$)$ \\
$\begin{array}{l}\text { Último uso hace más de cinco y } \\
\text { menos de diez años }\end{array}$ & $1,01(0,88$ a 1,16$)$ \\
\hline Último uso hace más de diez años & $0,9(0,72$ a 1,12$)$
\end{tabular}

Riesgo relativo de incidencia de cáncer de mama invasivo según el esquema recibido

\begin{tabular}{ll}
\hline Estrógenos solos & $1,30(1,22$ a 1,38$)$ \\
\hline Estrógenos más progesterona & $2 \quad(1,91$ a 2,09$)$ \\
\hline Tibolona & $1,45(1,25$ a 1,67$)$ \\
\hline
\end{tabular}

Riesgo relativo de incidencia de cáncer de mama invasivo según tiempo de uso en mujeres que usaban TRH combina . da durante el transcurso del estudio

\begin{tabular}{ll}
\hline Menos de 1 año & $1,45(1,19$ a 1,78$)$ \\
\hline 1 a 4 años & $1,74(1,60$ a 1,89$)$ \\
\hline 5 a 9 años & $2,17(2,03$ a 2,33$)$ \\
\hline Más de 10 años & $2,31(2,08$ a 2,56$)$ \\
\hline
\end{tabular}

Riesgo relativo de muerte por cáncer de mama

\begin{tabular}{ll}
\hline $\begin{array}{l}\text { No usadoras } \\
\text { del estudio }\end{array}$ & 1 \\
\hline Usadoras pasadas & $1,22(1,05$ a 1,21$)$ \\
\hline
\end{tabular}

\section{En conclusión}

Confirmamos una vez más que el uso de cualquier tipo de TRH aumenta la incidencia de cáncer de mama, aumentando el riesgo relativo con el tiempo de utilización. La TRH combinada cuadruplica el aumento de la incidencia de cáncer de mama con respecto al uso de estrógenos solos. La tibolona también aumenta el riesgo. No hubo diferencias respecto del tipo de estrógeno o progestágeno recibido, la dosis, la vía de administración (oral, transdérmica, implantada) ni por el tipo de régimen (secuencial o continuo).

El uso pasado de cualquier tipo de TRH no parece conferir un aumento del riesgo residual. El uso actual de TRH aumenta el riesgo de mortalidad por cáncer de mama.

Si se compara la incidencia acumulativa de riesgo de cáncer de mama invasivo en mujeres que usaron TRH con la incidencia de cáncer de mama de los países desarrollados, se desprende que si mil mujeres comenzaran a los 50 años a usar terapia combinada durante cinco años, se producirán de cinco a siete casos más de cáncer; y si lo hacen durante diez años, el exceso de cánceres será entre 18 y 20 cada mil usadoras.

\section{Principales aportes de este estudio}

- La tibolona, análogo estrogénico sintético al que se lo consideró una alternativa "segura" para el tratamiento de los síntomas menopáusicos, tambien confiere riesgos.

- Tiempo de TRH luego del cual aumenta la incidencia de cáncer. Ala luz de los trabajos anteriores, una de las pocas indicaciones que quedaba para la TRH era "...el tratamiento de los calores que afectaran la calidad de vida, utilizándolos por períodos cortos, ya que el aumento de la incidencia de cáncer de mama se apreciaba luego de tres años de tratamiento...". Sin embargo, en este estudio se observó rápidamente un aumento en la incidencia de cáncer de mama (durante el primer año de uso).

- No estaba todavía demostrado el impacto sobre la mortalidad.

\section{En resúmen}

Otro punto en contra para la TRH (incluyendo a la tibolona).

Dra. Mariela Barani [ Unidad de Medicina Familiar y Preventiva del Hospital Italiano de Buenos Aires ]

Referencias

1- Grady D, Herrington D, Bittner V et al. Heart and Estrogen / Progestin replacement Study (HERS II). JAMA2002, 288:49-57.

2- Women's Health Initiative randomized controlled trial. JAMA2002, 288: 321-333. 